\title{
Educação da infância: o lugar da participação da família na instituição educativa
}

\author{
Childhood education: family participation in the educational institution place \\ Educación de la infancia: el lugar de la participación de la familia en la \\ institución educativa
}

NANCY NONATO DE LIMA ALVES

Resumo: $\mathrm{O}$ artigo, que aborda a participação familiar como dimensão da gestão democrática na educação infantil, vincula-se à pesquisa Políticas públicas e educação da infância em Goiás: história, concepções, projetos e práticas. Com base no materialismo histórico-dialético, analisa a Educação Infantil como política pública e identifica contradições e desafios da participação da família nessa etapa educacional. Conclui que a democratização da gestão requer superar a participação restrita e operacional, construindo amplo envolvimento familiar nas decisões e ações políticas e pedagógicas da instituição de educação infantil.

Palavras-chave: Educação infantil; políticas públicas; participação familiar; gestão democrática.

\begin{abstract}
The article discusses the family participation as a dimension of democratic management in early childhood education and links to the search "Public policies and education of children in Goiás: history, concepts, projects and practices". Based on historical and dialectical materialism, examines early childhood education as a public policy and identify contradictions and challenges as the family's participatory forms in this educational stage. It concludes that the democratization of management requires overcoming restricted and operational participation, building the large family involvement in decisions and political and pedagogical actions of the early childhood institution.
\end{abstract}

Keywords: Childhood education; public policy; family participation; democratic management.

Resumen: El artículo abarca la participación de la familia como una dimensión de la gestión democrática en la educación infantil y está vinculado a la investigación "Políticas públicas y la educación de los niños en Goiás: historia, conceptos, proyectos y prácticas". Basado en el materialismo histórico y dialéctico, analisa la educación infantil como política pública e identifica las contradicciones y desafíos de la participación de la familia en esta etapa educativa. Se concluye que la democratización de la gestión requiere superar la participación restricta y operacional, construyendo amplia participación de la familia en las decisiones y acciones políticas y pedagógicas de la institución de educación infantil.

Palabras clave: Educación infantil; políticas públicas; participación de la familia; gestión democrática. 


\section{INTRODUÇÃO}

$\mathrm{Na}$ primeira metade do século XXI, a luta e a participação popular dos excluídos e oprimidos - continuam sendo um imperativo para enfrentar o recrudescimento das formas autoritárias e excludentes em variadas relações, instituições e dimensões da sociedade. Ao investigar a participação no campo educacional, rememoro o poema Elogio da Dialética, de Bertolt Brecht (1995, p. 149) como um mote para refletir acerca da luta e da participação: "Quem ainda é vivo, nunca diga: nunca! O mais firme não é firme. Assim como é não ficará. Depois que os dominantes tiverem falado, falarão os dominados. Quem ousa dizer: nunca? A quem se deve a duração da tirania? A nós. A quem sua derrubada? Também a nós. Quem será esmagado, que se levante! Quem está perdido, que lute?'. A luta constitui a possibilidade de existir, participar, ocupar espaços, construir práticas de inclusão, respeito, horizontalidade nas relações; por isso, é a luta pela igualdade entre as pessoas e pela garantia dos seus direitos. A proposição de políticas e de práticas participativas na educação também é reivindicação histórica da sociedade civil, uma luta de movimentos sociais, instituições e pessoas que almejam construir uma sociedade democrática e igualitária. Nessa perspectiva, a Constituição Federal (CF) reconhece a participação como direito e determina a gestão democrática como princípio da educação pública (BRASIL, 1988).

Desde a década de 1990, o tema da participação é recolocado nas políticas educacionais não somente pela mobilização social, mas também porque consta das orientações de organizações multilaterais para a agenda educacional brasileira. Com isso, configura-se o reconhecimento formal da necessidade do envolvimento dos pais na educação escolar dos filhos, aparentemente como estratégia de democratização da educação e de adequação da ação educativa à realidade e à cultura dos grupos sociais atendidos pelas instituições. Nesse contexto, é fundamental analisar e debater a participação das famílias na Educação Infantil na construção da gestão democrática, compreendendo a importância da instituição educacional como instância social não neutra, pois se insere na disputa hegemônica entre os projetos de sociedade de classes antagônicas.

As instituições de educação das crianças de zero até seis anos de idade ${ }^{1}$ no Brasil passam a ser consideradas formalmente nos sistemas de ensino somente na década de 1990, quando a Educação Infantil foi definida pela legislação como primeira etapa da Educação Básica. Consequentemente, a gestão dessas

1 Digo “até seis anos" porque é preciso reafirmar o direito à permanência na pré-escola para as crianças que completarem seis anos após a data limite para matrícula no Ensino Fundamental, atualmente fixada em 31 de março. Ressalto que essa defesa é assumida por movimentos sociais e pesquisadores, dentre os quais o Movimento Interfóruns de Educação Infantil do Brasil (MIEIB) e o Núcleo de Estudos e Pesquisas da Infância e sua Educação em Diferentes Contextos (NEPIEC/FE/UFG).

268 - RBPAE - v. 32, n. 1, p. 267 - 285, jan./abr. 2016 
instituições, historicamente vinculadas a outros setores das políticas sociais, sobretudo à assistência social, passa a se integrar no processo geral de gestão escolar nas redes municipais de educação (RME), sob a regulação específica da esfera educacional. Isso demanda a assunção de princípios comuns às demais escolas de ensino fundamental e/ou médio que constituem a rede de educação, dentre os quais a gestão democrática. É preciso considerar, entretanto, que a educação de crianças de até seis anos de idade possui peculiaridades em relação aos demais níveis de ensino, as quais devem expressar-se em propostas e práticas específicas de gestão e de trabalho pedagógico na creche e na pré-escola.

Com base no materialismo histórico-dialético (MARX, 2003), este artigo aborda criticamente a participação familiar na Educação Infantil, entendendo que a realidade é movimento contraditório e não linear. Busca compreender as mediações do objeto para além da imediaticidade posta na aparência, discutindo as concepções de educação, gestão e democracia, bem como os significados de participação da família que se expressam nas políticas educacionais, em projetos institucionais e por sujeitos do processo educativo. Para tanto, o texto analisa a Educação Infantil como política pública educacional constituída nas lutas sociais, discutindo conceitos de participação familiar em relação ao princípio da gestão democrática da educação. Destaca-se, ainda, que este estudo se vincula ao projeto de pesquisa Políticas públicas e educação da infância em Goiás: história, concepções, projetos e práticas, do Núcleo de Estudos e Pesquisas da Infância e sua Educação em Diferentes Contextos (Nepiec) da Faculdade de Educação (FE) da Universidade Federal de Goiás (UFG).

\section{“ASSIM COMO É NÃO FICARÁ. DEPOIS QUE OS DOMINANTES TIVEREM FALADO, FALARÃO OS DOMINADOS": REFLEXÕES SOBRE A CONSTRUÇÃO DA EDUCAÇÃO DA INFÂNCIA COMO POLÍTICA PÚBLICA}

As maneiras com as quais a sociedade considera as crianças e com elas se relaciona, assim como com a infância, são construções sócio-históricas integradas à organização política, cultural e socioeconômica; portanto, vinculadas à produção e reprodução da vida social. Nesse processo, é necessário considerar a atuação do Estado no provimento das necessidades dos distintos sujeitos sociais, configurada nas políticas públicas, as quais concretizam formas de ação, concepções e significados atribuídos a seus destinatários. As políticas sociais, conforme Rosemberg (2002) são "uma intervenção do poder público no sentido de ordenamento hierárquico de opções entre necessidades e interesses explicitados pelos diferentes segmentos que compõem a sociedade" (p. 29). Tendo em vista o 
papel fundamental de suporte ao capital exercido pelo Estado, assumindo, para tanto, interesses mercadológicos e privatistas, a incorporação e o atendimento de necessidades dos trabalhadores, das minorias sociais e dos grupos excluídos ocorrem quase que exclusivamente sob a pressão de movimentos organizados de segmentos sociais. Compreender políticas públicas educacionais exige, portanto, considerar a complexidade das relações entre Estado, sociedade e educação, analisando-se o significado do projeto social governamental, bem como os antagonismos no confronto entre trabalho e capital.

O reconhecimento das especificidades das crianças, como grupo social, fez-se necessário para alçá-las ao setor das políticas públicas, tornandoas campo de intervenção social e estatal. A política para a Educação Infantil brasileira constituiu-se de modo fragmentado em duas redes paralelas, nas quais o atendimento se diferencia conforme a esfera administrativa, as finalidades das propostas, a formação e o vínculo trabalhista do pessoal contratado, o tipo de funcionamento e a classe social de origem das crianças (HADDAD, 2007). O descaso do Estado acarretou a pulverização e a sobreposição de setores e órgãos responsáveis pela Educação Infantil; a provisão do atendimento e a criação de instituições por meio de medidas emergenciais e esporádicas; o insignificante aporte de recursos para financiamento e a falta de preocupação com a formação e qualificação dos profissionais, dentre outros problemas (BARBOSA, 2008; ROSEMBERG, 2002; HADDAD, 2007; ALVES, 2002, 2007).

Configurou-se o atendimento à infância por meio de creches e do préescolar. Diferenciadas pela vinculação administrativa - creches predominantemente no âmbito da Saúde e da Assistência Social; pré-escolar no âmbito da Educação - que acarretava distintas estruturas e condições desiguais, sobretudo no tocante aos profissionais. A trajetória das duas instituições, porém, acaba imbricando-se, com aproximação de concepções e de formas de funcionamento, ${ }^{2}$ especialmente no que se refere aos serviços públicos para as classes populares. A estas oferta-se uma educação precária, muitas vezes em locais improvisados, com trabalhadoras voluntárias e sem formação específica, sem recursos materiais e pedagógicos, priorizando-se a domesticação do corpo e das mentes, com propostas custodiais, compensatórias e moralizadoras. Enfim, uma educação pobre para pobres. Decorre, então, que não se pode entender o paralelismo da creche e do pré-escolar como resultante de sua "dupla origem" (HADDAD, 2007, p. 120), tampouco como separação total e/ou oposição radical entre elas. A diferenciação parece

2 A faixa etária de 3 a 6 anos, por exemplo, foi atendida tanto na creche, que recebia crianças a partir do nascimento até os seis, sete anos, quanto na pré-escola, no jardim de infância, na escola maternal. O funcionamento em período integral, característico da creche, também era ofertado por estas outras instituições, embora se caracterizassem predominantemente pelo período parcial.

270 - RBPAE - v. 32, n. 1, p. 267 - 285, jan./abr. 2016 
estabelecer-se pela classe social, constituindo contextos diferentes e desiguais para o desenvolvimento infantil.

A incorporação da teoria da privação cultural a partir das décadas de 1960 e 1970 explicita, nas ações oficiais para a Educação Infantil, o caráter compensatório de programas de creche e pré-escola, atribuindo-lhes a função de estimulação cognitiva e de preparação para a alfabetização, mais enfatizada nesta última, que passou a ser considerada também como alternativa de combate e prevenção ao fracasso escolar. Nota-se que, somente nesse período, a faixa etária anterior à escolaridade obrigatória foi incluída nos discursos dos órgãos públicos ligados à educação, inclusive na legislação educacional, como nas leis 4.024/1961 e 5.692/1971. As referidas leis abordam distintamente a educação pré-primária, mas nenhuma delas atribui ao Estado o dever de assegurar a educação das crianças menores de sete anos. Tal atendimento permanece marginal, ofertado prioritariamente, muitas vezes exclusivamente, para as famílias que não podiam assumir o cuidado dos próprios filhos, como era o caso das mães pobres trabalhadoras ${ }^{3}$.

$\mathrm{O}$ atendimento educacional à infância nas políticas públicas torna-se estratégia de subordinação das classes populares, "vital para o controle da convulsão social decorrente do agravamento das crises econômicas, da pobreza e da miséria da maioria da população do planeta" (BARBOSA; ALVES; MARTINS, 2005, p. 1). Tal visão, explicitada também nas orientações dos organismos internacionais (ROSEMBERG, 2002; MARQUEZ, 2006; BARBOSA, 2008), confronta-se com a resistência dos movimentos sociais que exigem dos governos a construção de uma política de Educação Infantil articulada aos interesses dos trabalhadores e das minorias sociais, que supere as medidas paliativas e emergenciais. Conforme indica Barbosa (2008) ao analisar as décadas de 1970 e 1980, a negociação, nesse jogo de forças e interesses antagônicos, resulta em políticas de consenso que acabam favorecendo a expansão da educação infantil, mesmo sem expressar real interesse transformador na discussão histórica sobre o campo. Nesse cenário, vêm sendo construídas e perpetuadas desigualdades de classe social, gênero, idade, étnicoraciais, localização geográfica e pedagógicas, além da baixa cobertura e qualidade do atendimento, evidenciadas em estatísticas oficiais e pesquisas (ROSEMBERG, 2002; CAMPOS; FÜLGRAFF; WIGGERS, 2006, dentre outras), e que desafiam todos os envolvidos na defesa das crianças e de sua educação.

É importante destacar o papel das mediações culturais - locais e nacionais - nas maneiras de organizar os serviços para a infância, dentre as quais, a visão de

3 Durante muitos anos, a matrícula da criança na creche em Goiás foi condicionada à permanência da mãe no emprego. A apresentação de carteira de trabalho assinada ou declaração do empregador era item obrigatório na documentação da criança na creche. 
família, da função feminina na sociedade e da criança. Diferentes respostas vêm sendo dadas à questão sobre a quem cabe a tarefa de socialização e formação das novas gerações. Uma destas considera a criança como responsabilidade privada da família, atribuindo especificamente à mãe o dever de educá-la. Daí a ideia de que a educação em espaços extradomiciliares deveria ser ofertada apenas quando a mãe não desempenhasse adequadamente sua função, por carência e/ou incapacidade econômica, moral, afetiva, cultural. A instituição se tornaria substituta familiar e a educadora substituiria a mãe. O mito da biologização da maternidade, no interior do qual toda mulher é considerada naturalmente apta e designada para a tarefa educativa, é transferido para o contexto institucional de educação e do cuidado infantil, resultando na ideia de mulher-mãe-educadora nata.

A trajetória da Educação Infantil é indissociável da história da mulher e das lutas femininas e feministas, dos movimentos sociais, do campo científicoacadêmico (CAMPOS, 1986; MIEIB, 2002; ROSEMBERG, 2002; BITTAR; SILVA; MOTTA, 2004; FARIA, 2005; BARBOSA, 2008; FINCO; GOBBI; FARIA, 2015; GEPEDISC, 2015). O próprio reconhecimento do direito à Educação Infantil insere-se em um movimento mais amplo de defesa dos direitos das crianças, obtendo conquistas legitimadas em documentos internacionais de grande importância, tais como a Declaração Universal dos Direitos da Criança (1959) e a Convenção Mundial dos Direitos da Criança (1989), dos quais o Brasil é signatário.

As mudanças econômico-culturais, como o ingresso feminino no mercado de trabalho, a urbanização e industrialização do país, bem como as lutas sociais por democratização e cidadania como direito, articuladas à pesquisa e à produção de conhecimentos sobre a infância e sua educação favorecem novas perspectivas de organização familiar e modificações nas maneiras de pensar a educação infantil. A mulher e a criança passam a ocupar o espaço público (SILVA, 2008), adquirem visibilidade, exigem direitos, reivindicam atenção adequada à satisfação de suas necessidades peculiares. Assim, a criação de creches para atender aos/às filhos/ as de mães trabalhadoras no período de 1950-1980 consistiu em uma estratégia governamental de controle social, mas também resultou da luta popular.

Na década de 1980 ampliaram-se os debates e as mobilizações populares pela democracia e pelos direitos dos cidadãos brasileiros, que tiveram como auge a promulgação de nova Constituição Federal (CF) em 1988, sob as premissas de Estado Democrático, reconhecendo a garantia dos direitos sociais e individuais, liberdade, segurança, bem-estar, desenvolvimento, igualdade e justiça como valores supremos de uma sociedade fraterna, pluralista e sem preconceitos (BRASIL, 1988). A inserção da criança como sujeito de direitos na CF/1988 resulta, igualmente, da pressão direta de movimentos e entidades sociais 
sobre os deputados constituintes e a opinião pública, em defesa das crianças e adolescentes. ${ }^{4}$ A partir de duas emendas de iniciativa popular, o artigo $227 \mathrm{da}$ CF/1988 incorpora a Doutrina de Proteção Integral, que também fundamenta o Estatuto da Criança e do Adolescente (ECA), aprovado em 1990, reafirmando direitos de provisão, proteção e participação das crianças e dos adolescentes (BRASIL, 1990). Não se pode minimizar a grandiosidade dessa conquista, ainda que sua materialização permaneça, em muitos aspectos, como horizonte a ser alcançado e, consequentemente, como foco de luta popular.

Quase uma década depois, em 1996, a Lei de Diretrizes e Bases da Educação Nacional (LDB), Lei 9.394, define que a Educação Infantil é a primeira etapa da Educação Básica, reiterando a noção de direitos da criança e da infância como etapa importante no processo de formação humana e de seu atendimento em creches e pré-escolas como dever do Estado. Isso anuncia a construção de conotação positiva para essas instituições, na tentativa de superar as noções de necessidade e incapacidade infantil, de carência e incompetência familiar. É necessário consolidar a imagem de criança como sujeito ativo, suprimindo a definição baseada em uma suposta natureza infantil, universal, que a considera inocente, desprovida de razão, dependente, incapaz de prover sua sobrevivência e, por isso, inferior; apenas um vir a ser que estaria em preparação para o exercício da cidadania quando se tornar adulto. Torna-se decisiva, também, a defesa de que o papel da instituição de educação infantil é compartilhar a educação das crianças, e não substituir a família.

Nesse percurso de construção da educação da infância como política pública, releva-se a criação e a atuação de instâncias consultivas e/ou deliberativas, como os Conselhos de Direitos das Crianças e dos Adolescentes, os Conselhos Tutelares e os Conselhos Municipais de Educação e de Assistência Social, assim como os Fóruns de Educação Infantil como entidades suprapartidárias e sua posterior articulação no Movimento Interfóruns de Educação Infantil do Brasil (MIEIB). Tais movimentos e órgãos têm assumido o protagonismo da defesa das crianças e de seus direitos, incidindo decisivamente em muitos encaminhamentos das políticas de Educação Infantil, entre outras políticas voltadas para a criança e a infância. Destaca-se, na atuação do MIEIB, dentre outros princípios compartilhados com os Fóruns de Educação Infantil, "a identificação da Educação Infantil enquanto campo intersetorial, interdisciplinar, multidimensional e em permanente evolução" (MIEIB, 2002, p. 11).

4 Por exemplo, a Pastoral do Menor da Conferência Nacional dos Bispos do Brasil (CNBB), o Movimento Nacional Meninos e Meninas de Rua (MNMMR), a Frente Nacional de Defesa dos Direitos das Crianças e Adolescentes, e a Comissão Nacional Criança e Constituinte. 
Contraditoriamente, a Educação Infantil é configurada, também, por ações restritivas dos direitos, apesar de proclamados na letra da lei. Merece análise crítica a forte influência da visão economicista, que busca identificar a educação como mercadoria que deveria ser produzida como as demais, ou seja, de acordo com as regras do mercado capitalista. A redução do papel do Estado nas políticas sociais integra essa visão nos chamados modelos alternativos ou não formais de Educação Infantil propugnados por organismos multilaterais, conforme explicita Rosemberg (2002): "No Brasil, essas propostas já foram incorporadas em passado recente e estão ameaçando o presente atual. A partir dos anos de 1970, essa influência proveio, especialmente, da Unesco [Organização das Nações Unidas para a Educação, a Ciência e a Cultura] e do Unicef [Fundo das Nações Unidas para a Infância]; a partir dos anos de 1990, a maior influência provém do BM [Banco Mundial]" (p. 29). Destaca ainda a autora que, minimizando o investimento do Estado e transferindo responsabilidades para a comunidade, tais modelos acarretam uma "sinergia perversa entre espaço inadequado, precariedade de material pedagógico e ausência de qualificação profissional da educadora, resultando em ambientes educacionais pouco favoráveis ao enriquecimento das experiências infantis" (Idem, p. 35).

Ademais, a formulação de um modelo de educação da infância articula expectativas e finalidades educativas, colocando em cena definições curriculares que podem privilegiar dimensões distintas do processo de desenvolvimento infantil, a partir do que se considera como resultado adequado da aprendizagem das crianças. Assim, no caso da Educação Infantil, é preciso, ainda, analisar criticamente a tendência que prioriza o ensino de conteúdos e comportamentos típicos das etapas seguintes da escolarização, na perspectiva de promover a aprendizagem de habilidades, tais como leitura, escrita, contagem e operações matemáticas. A prioridade, nesse caso, recai sobre o aspecto cognitivo, e não sobre o desenvolvimento integral da criança, descuidando das necessidades e maneiras de aprender próprias da faixa etária até seis anos de idade, como indicam pesquisas sobre o desenvolvimento infantil (VYGOTSKI, 2000; MUKHINA, 1996).

Analisando-se dialeticamente, do ponto de vista das contradições, reconhecem-se as conquistas das políticas públicas para a educação de crianças menores de seis anos: por exemplo, a exigência de formação e valorização dos professores e a definição de padrões de qualidade e de princípios pedagógicos que considerem as peculiaridades da aprendizagem e do desenvolvimento infantil. Tais ações favorecem a explicitação e a consolidação da identidade da Educação Infantil como etapa educacional com finalidade e características distintas do Ensino Fundamental, não se reduzindo-a a simples período preparatório, como momento de passagem, antessala para a escolarização posterior. Ao contrário, 
reafirma-se sua intencionalidade de promover o desenvolvimento integral da criança, complementando a ação da família e da comunidade. Nesse sentido, a gestão das instituições de Educação Infantil deve configurar-se considerando tanto sua distinção quanto sua articulação com demais níveis de ensino. A gestão democrática é traduzida na ideia de assegurar "a participação, o diálogo e a escuta cotidiana das famílias, o respeito e a valorização de suas formas de organização" (BRASIL, 2009a). Essa formulação reporta ao conceito de educação compartilhada, que requer reconhecer e construir o protagonismo e a participação familiar, bem como dos profissionais e da própria criança.

\section{"A QUEM SE DEVE A DURAÇÃO DA TIRANIA? A NÓS. A QUEM SUA DERRUBADA? TAMBÉM A NÓS”: DESAFIOS DA PARTICIPAÇÃO FAMILIAR E DA GESTÃO DEMOCRÁTICA NA EDUCAÇÃO INFANTIL}

A necessidade e a importância da participação familiar são amplamente reconhecidas na área da Educação Infantil, destacando-se que a promoção da qualidade e as especificidades da faixa etária das crianças exigem a parceria, o envolvimento de familiares no cotidiano da instituição educativa (SPAGGIARI, 1998; CORRÊA, 2001; HADDAD, 2002; OLIVEIRA, 2008; SAMBRANO, 2008, 2009; LOPES; GUIMARÃES, 2008; LARANJEIRA; GASPAR, 2008; OLIVEIRA; MACEDO, 2011; BONDIOLI; SAVIO, 2013, dentre outros). O caráter complementar entre a ação da instituição educativa e da família também é inserido nas políticas públicas, que estabelecem o direito de os pais e responsáveis conhecerem e participarem da elaboração, execução e avaliação da proposta pedagógica da instituição, além do direito de receberem informação sistemática e periódica acerca da aprendizagem e do desenvolvimento das crianças.

A discussão da gestão na Educação Infantil requer a compreensão da complexidade que constitui o atendimento e sua organização como política pública. A análise da participação familiar exige a compreensão da processualidade da Educação Infantil, considerando-se a presença histórica do modelo caritativomoralizador de substituição da família e de compensação de supostas carências originárias da (des)estrutura familiar (ALVES, 2007; BARBOSA; ALVES, 2009). O imbricamento da atuação de pais e educadores pode gerar situações conflitivas, de desconfianças e culpabilização recíprocas, o que constitui dificuldades para que a participação se efetive (OLIVEIRA; MELLO; VITÓRIA; FERREIRA, 1993; CORRÊA, 2001; HADDAD, 2002; SAMBRANO, 2008, 2009; LOPES; GUIMARÃES, 2008; LARANJEIRA; GASPAR, 2008). Por outro lado, a gestão democrática também se constitui em categoria complexa, pois sua efetivação no 
cotidiano escolar articula múltiplas dimensões, impõe a criação de mecanismos e instâncias colegiadas de participação coletiva nos processos decisórios, na definição, elaboração, execução e avaliação da proposta educativa, bem como no gerenciamento de recursos financeiros.

Em investigação acerca da coordenação pedagógica de Centros Municipais de Educação Infantil, realizada no projeto de pesquisa Políticas públicas e educação da infância em Goiás: história, concepcỗes, projetos e práticas, as profissionais entrevistadas indicaram desafios cotidianos na relação com as famílias, destacando-se a falta de tempo e a sobrecarga de trabalho dos pais, a pouca flexibilidade dos horários da instituição para promover encontros entre educadores e pais e outras situações que pudessem fomentar e ampliar a participação (ALVES, 2007). A referida investigação concluiu que os educadores parecem assumir uma concepção idealizada de família, adotando uma autoridade técnica que lhes confere superioridade perante os familiares; mostram-se refratários a críticas dos pais; e pretendem educar também as famílias, segundo valores e atitudes que consideram adequadas e corretas para a educação parental (ALVES, 2007; BARBOSA; ALVES, 2009). Mediante as mudanças socioculturais nos arranjos familiares, a própria definição de papeis e atribuições de professores e familiares não se apresenta fácil ou simples, uma vez que família e instituição são contextos fundamentais de desenvolvimento e educação da infância.

A perspectiva de educação compartilhada da criança em instituições coletivas desde seu nascimento problematiza a noção sociológica de socialização primária como tarefa exclusiva da família, pois, às vezes, a criança ingressa em ambas as instituições e delas participa simultaneamente, uma vez que, recémnascida, já frequenta a creche. Ao mesmo tempo, coloca-se em questão a especificidade da ação docente, na forma tradicional de aulas e transmissão de informações. Uma afirmativa corrente expressa tal inquietação, na tentativa de se separarem os papeis: a família educa, a escola ensina. É preciso refletir acerca dos significados atribuídos a educar e ensinar: de um lado, formação de limites, valores e disciplina como educação familiar e, de outro lado, o ensino como formação cognitiva na escola. Considerando que essas dimensões são indissociáveis na Educação Infantil, coloca-se o desafio de diferenciar e compartilhar a atuação de familiares e docentes. Em muitos casos, surge o questionamento acerca da legitimidade e da autoridade de familiares para tomar decisões no processo de ensino e aprendizagem. Qual seria o lugar da participação familiar?

A participação apresenta-se sob variadas perspectivas do ponto de vista conceitual, das políticas, das propostas e das experiências nos sistemas e instituições educativos. A polissemia e amplitude do termo resultam em uma diversidade de formulações acerca da gestão democrática, possibilitando 
"posturas de participação restrita e funcional atreladas às novas formas de controle social (qualidade total) até perspectivas de busca de participação efetiva e, consequentemente, de participação cidadã” (DOURADO, 2006, p. 79). O conceito de gestão democrática na Educação Infantil é fundamental para a criação das melhores e mais adequadas condições que apoiem as interações infantis, as quais são "o ponto central da mediação da aprendizagem das crianças" (OLIVEIRA, 2008, p. 126). Isso requer articular a participação ampla de educadores, familiares e da comunidade em geral nas decisões da instituição.

Também propugnada pororganizações multilaterais, a visão de participação restrita e operacional tem sido assumida em políticas públicas educacionais de cunho neoliberal e neotecnicista. As orientações do Banco Mundial enfatizam, por exemplo, o envolvimento e a participação dos professores para melhorar a qualidade da aprendizagem, exclusivamente centrada no processo de ensino, nos aspectos metodológicos (BANCO MUNDIAL, 1996), não abrangendo o processo decisório mais amplo. A participação familiar e da comunidade também é vista como condição de melhoria da qualidade da aprendizagem, na medida em que gera a satisfação e, principalmente, a contribuição dos pais para tornar a escola mais eficaz, em três aspectos: apoio financeiro, possibilidade de selecionar a escola e atuação na gestão. No entanto, o BM destaca que uma maior participação da família apresenta quatro riscos, podendo dificultar a projeção de objetivos nacionais amplos; aumentar a segregação social; favorecer a desigualdade, dependendo das condições econômicas da comunidade e das famílias; limitações decorrentes da falta de informação e de educação dos pais (BANCO MUNDIAL, 1996).

Notadamente, a abertura para que esses segmentos participem da instituição educacional prioriza o aspecto financeiro, para a redução de custos do Estado e, ainda, promover o sentimento de satisfação que os motivaria a contribuir para a obtenção de índices de desempenho estabelecidos nas políticas educacionais. Assim, o emprego de técnicas participativas para solucionar problemas e tomar decisões encorajaria docentes, pais e alunos a se responsabilizarem pelo que acontece na escola, quando for apropriado, isto é, quando interessar aos gestores. É o movimento denominado descentralização, que se torna desresponsabilização do Estado e transferência de encargos para a chamada comunidade, enquanto o controle e as decisões são cada vez mais centralizados.

A participação operacional abrange as concepções de parceria, nas quais o envolvimento dos familiares é visto como apoio financeiro, ajuda em tarefas relacionadas à manutenção do prédio, limpeza dos ambientes, trabalho voluntário em oficinas pedagógicas e atividades de enriquecimento curricular no contraturno, dentre outras formas utilitaristas que beneficiam a instituição, 
resolvendo problemas imediatos. Manifestar reconhecimento pelo trabalho realizado pelos educadores, colaborar com a preparação e frequentar as festas e os eventos também são ações valorizadas por profissionais de Educação Infantil, constituindo, ainda, indicadores para avaliar o interesse da família na educação dos filhos (ALVES, 2007; BARBOSA; ALVES, 2009). A integração das famílias ao projeto institucional proposto nos Referenciais Curriculares Nacionais para a Educação Infantil (BRASIL, 1998) - documento bastante conhecido como orientador das práticas pedagógicas - limita-se à necessidade de informar e sensibilizar os pais para aceitarem as opções e regras da instituição, previamente estabelecidas, mas não indica a participação familiar na elaboração e avaliação do projeto pedagógico. Nessa perspectiva moralizante e assistencialista, as famílias são coadjuvantes na execução de tarefas, esperando-se delas uma atitude de gratidão, sem questionamento ou reclamações.

Em pesquisa desenvolvida por Alves (2007) foi constatada a ambiguidade atribuída à participação familiar: se, por um lado, essa participação é considerada importante e necessária, apesar da necessidade de limites, pois a comunidade é, muitas vezes, politizada, por outro lado, é considerada uma relação difícil, pois a família estaria interessada em exigir seus direitos, e não em cumprir seus deveres. Além disso, conforme pontuou uma coordenadora pedagógica entrevistada pela pesquisadora, as famílias parecem querer ocupar o lugar dos profissionais e "mandar no CMEI, [porém] nem todos estão dispostos a fazer determinadas coisas para poder ajudar, nesse sentido que eu estou te falando, como, por exemplo, se pode contribuir na horta, de contribuir na capina" (ALVES, 2007, p. 165). Notase a contradição no movimento do real, em que a presença dos pais é necessária, desejada e temida. A instituição quer abrir-se para os familiares, mas receia que ocorram interferências em dimensões que seriam exclusivas dos profissionais. É preciso considerar o risco de ser construída a participação concedida, controlada e operacional, nos moldes preconizados pelos organismos internacionais, como o Banco Mundial.

A participação - familiar, dos professores, das crianças - possui significados pedagógicos e políticos, inserindo-se nas relações de poder, podendo, portanto, constituir-se como contrarregulação, ou seja, como "resistência propositiva que cria compromissos ancorados na comunidade mais avançada da escola (interna e externa), com vistas a que o serviço público se articule com seus usuários [...] tendo como norte a convocação de todos para o processo de transformação social” (FREITAS, 2005, p. 912). Nessa perspectiva de gestão democrática, a participação ocorre na totalidade do processo educativo, sobretudo na tomada de decisões na gestão administrativa, pedagógica e financeira. 
Compreendo a gestão escolar como prática sociopolítica e educativa que constitui, no coletivo da instituição, valores, atitudes, modos de agir e de pensar os processos e práticas educativas escolares. Dessa maneira, "não se apresenta uniforme, pois expressa sempre a correlação de forças entre as diretrizes emanadas do sistema educativo e as ações efetivas dos diferentes atores das comunidades local e escolar" (DOURADO 2003, p. 18-19). A gestão configura-se como espaço privilegiado de encontro e, por vezes, de embates entre o Estado e a sociedade civil na escola (KRAWCZYK, 1999; DOURADO, 2003); é marcada, portanto, por relações de poder que se estabelecem na instituição, no sistema educativo e na sociedade em geral. Distinguir e distanciar a administração educacional e a empresarial é necessário, impregnando a gestão da educação das finalidades pedagógicas e recusando a subordinação aos princípios de mercado (KRAWCZYK, 1999; PARO, 2003; DOURADO, 2003). Como os princípios da organização das empresas são direcionados para o lucro, com a exploração do trabalho do homem, a gestão da educação não pode render-se às exigências de produtividade mercadológica, pois deve compreender a formação omnilateral para o desenvolvimento da capacidade realizadora e criadora do homem, em todas as suas dimensões (ALVES, 2007).

Com base na concepção de qualidade processual, histórica, cultural e situada nas condições objetivas locais, o documento do MEC Indicadores da Qualidade na Educação Infantil aproxima a participação à qualidade, propondo que o processo de definição e avaliação desta na instituição educativa deva "ser participativo e aberto, sendo importante por si mesmo, pois possibilita a reflexão e a definição de um caminho próprio para aperfeiçoar o trabalho pedagógico e social das instituições" (BRASIL, 2009b, p. 12). A participação da família é referida explicitamente em cinco das sete dimensões que compõem a metodologia avaliativa proposta no documento, uma das quais trata especificamente da cooperação e da troca com as famílias. De maneira geral, os indicadores dessas dimensões abordam o acolhimento, inclusive, com espaços e horários adequados para receber as famílias; as relações de respeito, amizade e valorização recíprocas; a possibilidade de acompanhamento das vivências das crianças na instituição, com apresentação periódica de planejamentos e das produções das crianças e entrega de relatórios; o conhecimento e a participação de familiares na elaboração e atualização da proposta político-pedagógica; e a inclusão dos saberes das famílias nas atividades pedagógicas. Reconhece-se a relevância da proposta dos Indicadores, mas se nota que a dimensão política da participação como gestão democrática é pouco explicitada no documento, que privilegia a dimensão pedagógica destinada à formação da criança. 
Para efetivar a participação das famílias, é indispensável assegurar-lhes reais condições de envolver-se, estar presente e realizar ações conjuntas. Dentre essas condições, destacam-se: horários alternativos de reuniões, acesso à informação, respeito às opiniões, abertura para o dissenso. Assim, também são necessárias condições para os educadores, com tempo remunerado e formação contínua que lhes dê segurança e domínio para propor e realizar coletivamente as situações participativas com a família, tais como as reuniões de pais, o contato diário, as diferentes formas de comunicação, as festas e comemorações. Tal garantia, porém, parece estar sendo delegada às próprias instituições de Educação Infantil e a seus profissionais, sem referência clara à responsabilidade que as instâncias centrais devam assumir (ALVES, 2007). Nesse sentido, "há que se insistir na ausência do poder público, uma vez mais, como um dos maiores responsáveis pela falta de formação e de condições dignas de trabalho" (CORRÊEA, 2001, p. 181).

É preciso, portanto, reconhecer as iniciativas das instituições e dos/das profissionais para constituir formas participativas de conviver, escutar, dialogar com as famílias acerca do projeto educativo proposto pela instituição (ALVES, 2007; BARBOSA; ALVES, 2009). Outra forma de luta pela democratização é, ainda, opor-se a toda forma de culpabilização e responsabilização externa dos profissionais por limites e equívocos que dificultam a democratização da Educação Infantil.

\section{CONSIDERAÇÕES FINAIS}

Destaco a importância de explicitar e compreender dialeticamente as mediações e contradições da participação e da gestão democrática na Educação Infantil, reconhecendo os condicionamentos materiais e simbólicos desses processos. A democratização não pode ser simplesmente decretada; ao contrário, é construída nas condições concretas de realização do ato educativo, ressignificando e assegurando o cumprimento, com qualidade, de sua função social. Assim, a gestão escolar democrática precisa considerar a participação de diferentes segmentos e pessoas na escola e no sistema de ensino, o trabalho coletivo, a eleição direta de diretores, a autonomia de profissionais e da instituição, a construção participativa da proposta político-pedagógica e a criação e efetivação de mecanismos colegiados para a tomada de decisões.

A trajetória da Educação Infantil se fez e se faz na luta contra a opressão, pelos direitos das crianças e pela participação social em condições de igualdade. As mudanças precisam ser construídas na articulação e materialização de uma política pública consistente, contínua, intersetorial e articulada com a sociedade civil. O direito de toda criança de receber cuidados e educação com qualidade impõe 
a superação da precariedade na realização do atendimento e o enfrentamento das polarizações que marcam a área. A luta pela democratização dos espaços, das vozes, das posições decisórias precisa traduzir-se na gestão democrática e participativa em uma perspectiva transformadora, de igualdade e de superação das hierarquias e da dominação de qualquer tipo. Reafirmo, pois, o convite do poeta para que continuemos a luta: "Quem será esmagado, que se levante! Quem está perdido, que lute?'.

\section{REFERÊNCIAS}

ALVES, Nancy N. de L. Coordenação pedagógica na Educação Infantil: trabalho e identidade profissional na rede municipal de ensino de Goiânia. 2007. 315 f. Tese (Doutorado em Educação) - Faculdade de Educação, Universidade Federal de Goiás. Goiânia, 2007.

Elementos mediadores e significativos da docência em educação infantil da rede municipal de ensino de Goiânia. 2002. 205 f. Dissertação (Mestrado em Educação) - Faculdade de Educação, Universidade Federal de Goiás. Goiânia, 2002.

ARAÚJO, Denise S. Infância, família e creche: um estudo dos significados atribuídos por pais e educadoras de uma instituição filantrópica. 2006. 265 f. Tese (Doutorado em Educação) - Universidade Federal de Goiás. Goiânia, 2006.

BANCO MUNDIAL. Prioridades y Estratégias para la Educación - examen del Banco Mundial. Washington, D.C., 1996. (versão em espanhol).

BARBOSA, Ivone G. Das políticas contraditórias de flexibilização e centralização: reflexões sobre a história e as políticas da educação infantil. Inter-Ação, v. 33, n. 2, p. 379-393, jul./dez. 2008.

; ALVES, Nancy N. L.; MARTINS, Telma A. T. Políticas públicas para a Educação Infantil em Goiânia: a luta por um projeto político-social. 28 ${ }^{\mathbf{a}}$ Reunião Anual da Anped. Anais. Caxambu, 2005.

; ALVES, Nancy N. L. Gestão democrática na educação infantil e participação da família: possibilidades e limites. XXIV Simpósio Brasileiro de Política e Administração da Educação, III Congresso Interamericano de 
Política e Administração da Educação. Anais. Vitória: Universidade Federal do Espírito Santo, 2009.

BITTAR, Mariluce; SILVA, Jória P. de O.; MOTTA, Maria Cecília A. formulação e implementação da política de educação infantil no Brasil. In: RUSSEFF, Ivan; BITTAR, Mariluce (orgs.). Educação Infantil: política, formação e prática docente. Brasília: Plano, 2004.

BONDIOLI, Anna; SAVIO, Donatella (orgs.). Participação e qualidade em educação da infância - percursos de compartilhamento reflexivo em contextos educativos. Curitiba: Ed. UFPR, 2013

BRASIL. Conselho Nacional de Educação (CNE). Resolução CNE/CEB no 05/2009. Fixa as Diretrizes Curriculares Nacionais para a Educação Infantil. Brasilia: MEC: 2009a.

- Ministério da Educação (MEC). Indicadores da Qualidade na Educação Infantil. Brasília, 2009b.

. Lei $\mathrm{n}^{0}$ 9.394, de 20 de dezembro de 1996. Estabelece as diretrizes e bases da educação nacional. Brasília: Imprensa Nacional, 1996.

Lei $\mathrm{n}^{\circ} \mathbf{8 . 0 6 9}$, de 13 de julho de 1990. Dispõe sobre o Estatuto da Criança e do Adolescente e dá outras providências. Brasília, 1990.

Ministério da Educação (MEC). Referenciais Curriculares Nacionais para a Educação Infantil. Brasília: MEC, 1998. 3 v.

. Constituição da República Federativa do Brasil. Brasília, 1988. Disponível em: <http://www.planalto.gov.br/ccivil_03/Constituicao/ Constituicao.htm> Acesso em: 5 nov. 2015.

BRECHT, Bertolt. Elogio da dialética. In: CAMPOS, Haroldo. Breve antologia de Bertolt Brecht. Fragmentos, v. 5, n. 1, p. 143-155, 1995. Disponível em: < https://periodicos.ufsc.br/index.php/fragmentos/article/view/4909/4270>. Acesso em: 15 nov. 2015.

CAMPOS, Maria M. Malta. A Constituinte e a educação da criança de 0 a 6 anos. Cadernos de Pesquisa, v. 59, p. 57-65, nov. 1986.

282 - RBPAE - v. 32, n. 1, p. 267 - 285, jan./abr. 2016 
; FÜLGRAFF, Jodete; WIGGERS, Verena. A qualidade da Educação Infantil brasileira: alguns resultados de pesquisa. Cadernos de Pesquisa, v. 36, n. 127, p. 87-128, jan./abr. 2006.

CORRÊA, Bianca C. Possibilidades de participação familiar e qualidade na educação infantil. 2001. 192 f. Dissertação (Mestrado em Educação) Universidade de São Paulo. São Paulo, 2001.

DOURADO, Luiz F. Escolha de dirigentes escolares: políticas e gestão da educação no Brasil. In: FERREIRA, N. S. C. (org.) Gestão democrática da educação: atuais tendências, novos desafios. 5. ed. São Paulo: Cortez, 2006.

(Org.). Gestão escolar democrática: a perspectiva dos dirigentes escolares da rede municipal de ensino de Goiânia-GO. Goiânia: Alternativa, 2003.

FARIA, Ana Lúcia G. Políticas de regulação, pesquisa e pedagogia na Educação Infantil, primeira etapa da Educação Básica. Educação \& Sociedade. v. 26, n. 92, p. 1013-1038, Especial - Out. 2005. Disponível em <http://www.cedes. unicamp.br> Acesso em ago/2006.

FINCO, Daniela; GOBBI, Marcia A.; FARIA, Ana Lúcia G. Creche e feminismo: desafios atuais para uma educação descolonizadora. Campinas, SP: Leitura Crítica/ São Paulo: ABL/ FCC, 2015.

FREITAS, Luiz C. Qualidade negociada: avaliação e contra-regulação na escola pública. Educação \& Sociedade, v. 26, n. 92, p. 911-933, out. 2005. Edição Especial.

GEPEDISC. (Linha Culturas Infantis). Infâncias e movimentos sociais. Campinas, SP: Leitura Crítica, 2015.

HADDAD, Lenira. A trajetória da Educação Infantil em quatro ciclos. In: XAVIER, Maria Elizabete P. S. Questões de Educação Escolar. São Paulo: Alínea, 2007.

A creche em busca de identidade. 3. ed. São Paulo: Loyola, 2002.

KRAWCZYK, Nora. A gestão escolar: um campo minado... Análise das propostas de 11 municípios brasileiros. Educação \& Sociedade. Ano XX, n. 67, p. 112149, ago. 1999. 
LARANJEIRA, Rita A. S. R.; GASPAR, Maria Filomena R. da F. O envolvimento da família no Jardim de Infância: perspectivas dos pais em Portugal. In: GUIMARÃES, Célia M.; RIBEIRO, Arilda I. M. (orgs.). Gestão educacional: questões contemporâneas. Araraquara, SP, Junqueira \& Marin; Presidente Prudente, SP: Fundacte, 2008.

LOPES, Claudia C. G. P.; GUIMARÃES, Célia M. (Re)pensando as relações entre instituições de educação infantil e famílias. In: GUIMARÃES, Célia M.; RIBEIRO, Arilda I. M. (Orgs.). Gestão educacional: questões contemporâneas. Araraquara, SP: Junqueira \& Marin; Presidente Prudente, SP: Fundacte, 2008.

MARX, Karl. Contribuição à crítica da economia política. 3 ed. São Paulo: Martins Fontes, 2003.

MARQUEZ, Christine G. O Banco Mundial e a Educação Infantil no Brasil. 2006. 215f. Dissertação (Mestrado em Educação) - Faculdade de Educação, Universidade Federal de Goiás. Goiânia, 2006.

MIEIB. Educação Infantil: construindo o presente. Campo Grande: Ed. UFMS, 2002. (Movimento Interfóruns de Educação Infantil)

MUKHINA, Valeria. Psicologia da idade pré-escola. São Paulo: Martins Fontes, 1996.

OLIVEIRA, Zilma de M. Gestão pedagógica das instituições de educação infantil. In: GUIMARÃES, Célia M.; RIBEIRO, Arilda I. M. (orgs.). Gestão educacional: questões contemporâneas. Araraquara, SP: Junqueira \& Marin; Presidente Prudente, SP: Fundacte, 2008.

; MELLO, Ana Maria; VITÓRIA, Telma; FERREIRA, Maria Clotilde R.. Creches: crianças, faz de conta \& cia. Petrópolis: Vozes, 1993.

OLIVEIRA, Heloisa H. G.; MACEDO, Lino. Reuniões de pais na Educação Infantil: modos de gestão. Cadernos de Pesquisa, v. 41, n. 142, p. 208-227, jan./ abr. 2011.

PARO, Vitor H. Gestão democrática da escola pública. 3. ed. São Paulo: Ática, 2003.

284 - RBPAE - v. 32, n. 1, p. 267 - 285, jan./abr. 2016 
ROSEMBERG, Fúlvia. Organizações multilaterais, Estado e políticas de Educação Infantil Cadernos de Pesquisa, n. 115, p. 25-63, mar. 2002.

SAMBRANO, Taciana M. (Com)vivendo com crianças e suas famílias: desafios para o educador? In: ANGOT'TI, Maristela (org.). Educação Infantil: da condição de direito à condição de qualidade no atendimento. São Paulo: Alínea, 2009

. Relação instituição de Educação Infantil e família: um sonho acalentado, um vínculo necessário. In: ANGOTTI, Maristela (org.). Educação Infantil: para que, para quem e por quê? São Paulo: Alínea, 2008.

SILVA, Isabel de O. Educação Infantil no coração da cidade. São Paulo: Cortez, 2008.

SPAGGIARI, Sérgio. Considerações críticas e experiências de gestão social. In: BONDIOLI, A.; MANTOVANI, S. Manual de educação infantil: 0 a 3 anos uma abordagem reflexiva. 9. ed. Porto Alegre: Artmed, 1998.

VYGOTSKI, Lev S. Obras escogidas III - Problemas del desarrollo de la psique. 2 ed. Madri: Aprendizage Visor, 2000.

NANCY NONATO DE LIMA ALVES é doutora em Educação (UFG/2007), mestre em Educação (UFG/2002) e possui especialização em Psicopedagogia (UFG/1996). Graduação em Pedagogia (PUC-GO/1991). Professora da Faculdade de Educação/UFG, na área de Didática, Formação de Professores e Estágio nos Anos Iniciais do Ensino Fundamental e Educação Infantil do curso de Pedagogia e no Programa de Pós-Graduação em Educação (PPGE/ FE). Subcoordenadora do Núcleo de Estudos e Pesquisas da Infância e sua Educação em Diferentes Contextos (NEPIEC). Vice-Coordenadora do Projeto de Pesquisa "Políticas públicas e educação da infância em Goiás: história, concepções, projetos e práticas". Coordenadora do curso de Especialização em Educação Infantil (2014-2016). E-mail: nancynlalves@gmail.com

Recebido em novembro de 2015 Aprovado em janeiro de 2016 